\title{
Prevalence of Maxillofacial and Skeletal Anomalies at Children Born in Regions Endemic to Fluorosis
}

\section{Taincha Talibova ${ }^{1}$ and Dilbar Mehdi ${ }^{2 *}$}

${ }^{1}$ Department of Orthopedic Dentistry of the Azerbaijan Medical University, Azerbaijan

${ }^{2} 4^{\text {th }}$ Year Undergraduate Student at the University of Wyoming, USA

*Corresponding Author: Dilbar Mehdi, $4^{\text {th }}$ Year Undergraduate Student at the University of Wyoming, USA.
Received: October 22, 2021

Published: November 23, 2021

(C) All rights are reserved by Taincha Talibova and Dilbar Mehdi.

\section{Abstract}

Summary: The goal of this study was to determine the prevalence of maxillofacial and skeletal defects in regions endemic to fluorosis.

A retrospective chart review over the period from 2011 till 2020 was conducted on 38,460 postpartum medical records from regions endemic for fluoride excess (fluoride level over $1.4 \mathrm{mg} / \mathrm{L}$ ); the control group consisted of 1787 postpartum records from region with normal levels of fluoride $<0.8 \mathrm{mg} / \mathrm{L}$.

Results: In regions endemic to fluorosis the prevalence of maxillofacial defects was 0.83 , and prevalence of other associated skeletal anomalies was 7.5 per 1000 newborns. No maxillofacial defects were reported in the control group.

The toxic impact of fluoride excess in drinking water was associated with other metabolic disruptions- majotiry of women with elevated fluoride exposire had anemia; endemic Grave’s disease in this area was $72.7 \pm 9.5 \%$.

Conclusion: Awareness of the potential toxicity of fluoride in drinking water is essential as associated fetal malformations could be prevented by exposure reduction and water quality control.

Keywords: Maxillofacial; Skeletal Defects; Fluoride Toxicity’ Pregnancy

\section{Background}

Despite the opinion of many authors about the genetic origin of congenital anomalies, the etiology and pathogenesis of maxillofacial and skeletal defects needs to be investigated further [1,2]. The increase of developmental defects could be related to the abundance of toxic substances such as manganese, cadmium, lead, and/or fluoride [3-10] co-morbidities (anemia, hypothyroidism) $[11,12]$; diet, folate and iodine deficiency; and other factors potentially affecting intrauterine growth [1-3,6,8-10,12-14].

Systemic congenital deficiencies and organ malformations that resulted of multifactorial metabolic defects could be prevented if/ when identified timely.

\section{Research goals}

To determine the prevalence of congenital maxillofacial and skeletal defects in pregnant women that live in regions endemic to fluorosis (fluoride over $1.4 \mathrm{mg} / \mathrm{L}$ in drinking water); the control group has normal fluoride levels $(<0.8 \mathrm{mg} / \mathrm{L}$.)

\section{Materials and Methods}

A retrospective review was conducted on 38,460 postpartum records of women with confirmed elevated fluoride exposure over the period of 2011-2020. The control group had 1787 postpartum women from regions with normal levels of fluoride in drinking water over the same period of time. Among women who gave birth to children with maxillofacial and skeletal abnormalities, secondary 
review was performed for clarification of observed data based on the available laboratory, biochemical and clinical results prior and during pregnancy.

\section{Results, Discussion and Conclusion}

In zones endemic to fluorosis diversity of maxillofacial abnormalities were documented, including and none limited to orofacial cleft with uni-and bilateral lip/palate defects (Figure 1 and 2); isolated lesion of the soft palate; micrognathia - with a defect in the lower jaw; cleft upper lip - bilateral, unilateral; dermoid cyst, macroglossia and ankyloglossia (11.1 $\pm 1.85 \%$ of all lesions).

Associated skeletal abnormalities (Spina bifida (Figure 3,4), hips dysplasia, polydactyly, adactyly, syndactyly etc.) were documented in 7.5 cases per every 1000 newborns. Significant percentage of neonates in this group were small for gestational age.

Secondary review of peripartum history in this group revealed that in $36.4 \pm 10.26 \%$ of cases, pregnancy was accompanied by anemia; $22.7 \pm 8.93 \%$ - endemic Grave's disease.

$18.2 \pm 8.22 \%$ - genetic factors; $13.6 \pm 7.32 \%$ - threatened miscarriage, infectious disease, leukemia, calculous cholecystitis; $9.1 \pm$ $6.13 \%$ - had consanguineous marriages.

In the control group, the rate of skeletal anomalies was 5.6 per 1000 newborns. Maxillofacial anomalies were not detected, isolated defects of the musculoskeletal system were encountered - dislocation of the hip joint and polydactyly.

There were no more than two cases of congenital anomalies in single case. High correlation between worsening of endemic Grave's disease during pregnancy that was noted in the group with high fluoride levels in drinking water.

Congenital maxillofacial anomalies, as well as skeletal deformities, were more common in areas endemic to fluorosis. Excess fluoride in drinking water may trigger the mechanism for skeletal defects via alteration of alkaline phosphates activity and mitochondrial damage.

For prophylaxis in fluorosis-endemic regions it is vital to determine $\alpha$-fetoprotein in the second trimester of pregnancy, and conduct regular ultrasonography (Figure 4) from the $2-3^{\text {rd }}, 10-13^{\text {th }}$, $16-22^{\text {nd }}$ weeks of pregnancy, especially in pregnant women with obvious signs of dental fluorosis (Figure 5).
A retrospective analysis of congenital anomalies showed:

- In the exposure group (fluorosis-endemic regions) - 0.83 cases of defects of the maxillofacial region per 1000 newborns; - 7.5 skeletal anomalies per 1000 newborns.

- $\quad$ The greatest $72.7 \pm 9.5 \%$ of the cases of the mothers suffered from concomitant diseases (anemia, endemic Grave's disease) was observed in. In which they had children with maxillofacial anomalies.

- In the control group - 5.6 cases of isolated defects of the osteoarticular system per 1000 born children; no maxillofacial anomalies were found.

- Studies prove a multifactorial etiology of congenital anomalies but focus on the effect of concomitant pathology caused by toxic concentration of fluoride in drinking water.

Fluorine initially has a toxic effect on the body [12-15]. Moreover, prolonged residence in a region with the excess of fluoride (1.4 $\mathrm{mg} / \mathrm{L}$ and above) causing irreversible damage on the endocrine system, affects iodine, iron and calcium absorption, worsens anemia and Graves disease.

It has been established that fluoride compounds partially penetrate the placenta and can accumulate in the fetal issues from first trimester [15]. Accumulating in the body, fluoride compounds have a toxic effect on the body by inhibiting activity of alkaline phosphatase and disrupting the structure of the skeleton. On the cellular level, fluoride exposure decreases mitochondrial activity, reduces numbers of free ribosomes, and causes dilation of rough-surfaced endoplasmic reticulum [14-16].

Our study focuses on prevalence of maxillofacial and skeletal anomalies in newborns from fluorosis-endemic zone, and it supports the idea that fluoride exposure reduction and control could be the effective way to prevent development of these devastation malformations. Cost-effective study could be conducted on the existing data, and most probably will help create effective preventive guidelines.

Why this paper is important for pediatric dentists

- The article emphasizes the importance of antenatal diagnosis of maxillofacial anomalies in women living in regions endemic to fluorosis. 


\begin{tabular}{|l|c|}
\hline Causes & Cases \% \\
\hline Anemia & $36.4 \pm 10.26$ \\
\hline Endemic Grave's disease & $22.7 \pm 8.93$ \\
\hline Genetic factors & $18.2 \pm 8.22$ \\
\hline $\begin{array}{l}\text { Threatened miscarriage, } \\
\text { infectious disease, leukemia, } \\
\text { calculous cholecystitis }\end{array}$ & $13.6 \pm 7.32$ \\
\hline Consanguineous marriages & $9.1 \pm 6.13$ \\
\hline
\end{tabular}

Table 1: Associated health issues in mother of infants with maxillofacial anomalies (Fluoride exposure group).

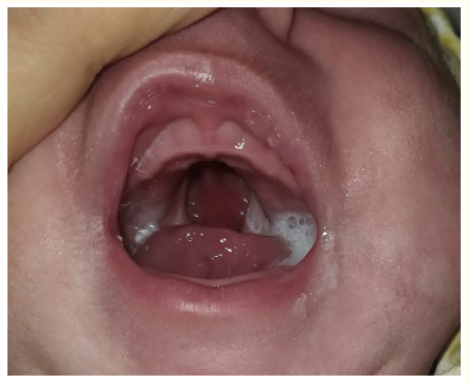

Figure 1: Congenital form of orofacial cleft of hard and soft palate.

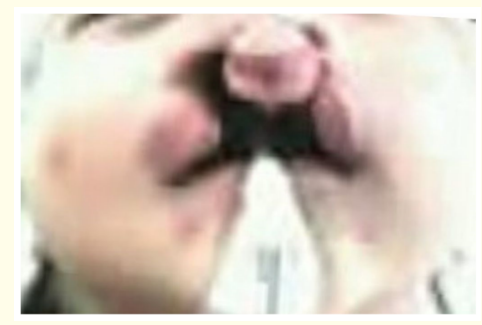

Figure 2: Congenital both-sided cleft of the upper lip, hard, and soft palate.

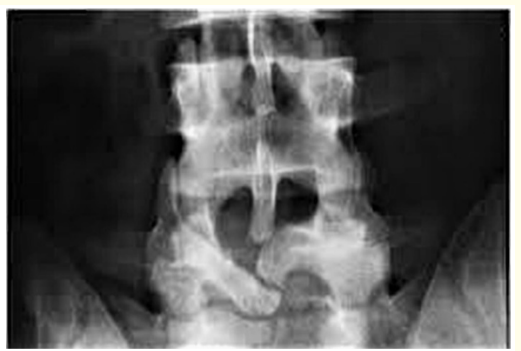

Figure 3: Congenital Spina bífida.

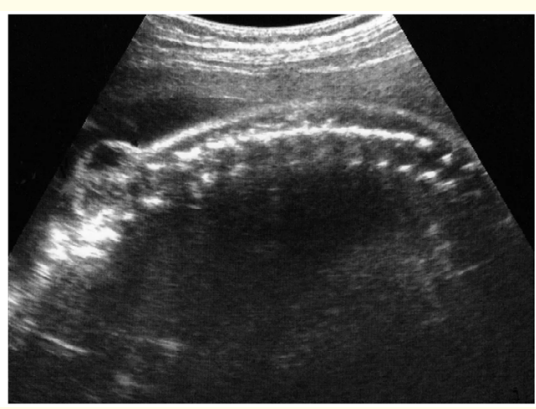

Figure 4: Antenatal diagnosis of fetoplacental malformations.

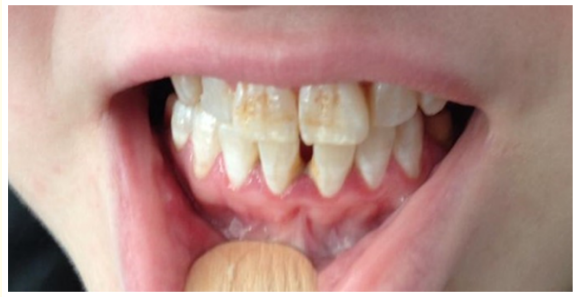

Figure 5: Spots due to dental fluorosis.

- $\quad$ Bring the women of reproductive age with teeth fluorosis and comorbidities such as Grave's disease or anemia.

- The significance of further studies of antenatal period of fetal development to maintain the health of the child population.

Many thanks to the head of Orthopedic dentistry department, professor Panahov N.A. for the help and support in scientific research.

Parental/patients consents was obtained for photographs publication and available to review.

\section{Bibliography}

1. Sperber GH. "Craniofacial Development”. BC Decker; Hamilton, ON, Canada (2000).

2. Mossey P and Castilla E. "Report of a WHO Registry Meeting on Craniofacial Anomalies. World Health Organization; Geneva, Switzerland". Global Registry and Database on Craniofacial Anomalies (2003).

3. Mossey PA., et al. "Cleft Lip and Palate". Lancet 374 (2009): 1773-1785. 
4. Townsend G and Brook A. "Genetic, epigenetic and environmental influences on dental development". Ortho Tribune 3 (2008): 4-6.

5. Nanci A. “Ten Cate's oral histology: development, structure, and function". Elsevier Health Sciences (2014).

6. Howe AM., et al. "The Growth of the Nasal Septum in the 6-9 Week Period of Foetal Development-Warfarin Embryopathy Offers a New Insight into Prenatal Facial Development". Australian Dental Journal 49 (2004): 171-176.

7. Katsube M., et al. "Critical Growth Processes for the Midfacial Morphogenesis in the Early Prenatal Period". The Cleft PalateCraniofacial Journal 56 (2019): 1026-1037.

8. Hartman C., et al. "Nasal Septal Deviation and Facial Skeletal Asymmetries". The Anatomical Record 299 (2016): 295-306.

9. Goergen MJ., et al. "Morphological Interaction between the Nasal Septum and Nasofacial Skeleton during Human Ontogeny". Journal of Anatomy 230 (2017): 689-700.

10. Mousa A., et al. "Macronutrient and micronutrient intake during pregnancy: An overview of recent evidence". Nutrients 11 (2019): 443.

11. Talibova $\mathrm{T}$ and Mehdiyeva F. "Somatic pathology, endemic teeth fluorosis". Cathedra (2020): 72-73.

12. Gernand AD., et al. "Micronutrient deficiencies in pregnancy worldwide: Health effects and prevention". Nature Reviews Endocrinology 12 (2016): 274.

13. Godswill AG., et al. "Health Benefits of Micronutrients (Vitamins and Minerals) and their Associated Deficiency Diseases: A Systematic Review". International Journal of Food Science 3 (2020): 1-32.

14. Gupta SK., et al. "Increased incidence of spina bifida occulta in fluorosis prone areas". Acta Paediatrica Japonica 37.4 (1995): 503-506.

15. He H., et al. "Effects of fluorine on the human fetus". Fluoride 4.3 (1989): 136-138.

16. Kanduti D., et al. "Fluoride: A review of use and effects on health. Mater". Sociomedical 28 (2016): 133-137.

Volume 5 Issue 12 December 2021

(C) All rights are reserved by Taincha Talibova and Dilbar Mehdi. 